\title{
O planejamento territorial participativo (PTP) e o PAC em disputa para o desenvolvimento da região de integração do Carajás - Pará
}

\author{
Rafael Gonçalves Gumiero \\ Universidade Federal do Sul e Sudeste do Pará - Marabá - PA - Brasil \\ ORCID: https://orcid.org/0000-0002-6193-8698
}

\section{Resumo}

Este artigo apresenta o balanço dos impactos das políticas públicas balizado pela mensuração dos projetos e investimentos das escalas estadual e federal, nos anos 2008 a 2018, na sub-região de Carajás, no Pará. Na escala estadual foi analisado se houve inserção dos projetos do Planejamento Territorial Participativo (PTP) no Plano Plurianual 2008-2011. $\mathrm{Na}$ escala federal foram sistematizados os impactos dos projetos do Programa de Aceleração do Crescimento (PAC) no território. Os documentos analisados foram os relatórios do PAC do Pará, e os relatórios estaduais do PPA 2008-2011 formulados pela Secretaria de Estado de Planejamento, Orçamento e Finanças (SEPOF). O resultado reforçou a concentração de projetos do PPA 2008-2011 na região Metropolitana do Pará e os empreendimentos do PAC foram desconcentrados dela, porém foram direcionados atendendo as vantagens comparativas de recursos naturais e a mitigação ambiental e social do impacto dos grandes projetos de infraestrutura na sub-região de Carajás.

Palavras-chave: PAC. Planejamento Estratégico Participativo. Carajás. Plano Plurianual. Pará.

The participatory territorial planning (PTP) and the PAC in dispute for the development of the Carajás integration region - Pará

\section{Abstract}

This article presents the balance of the impacts of public policies based on the measurement of projects and investments at the state and federal scales, in the years 2008 to 2018, in the sub-region of Carajás, in Pará. On the state scale, it was analyzed whether the Participatory Territorial Planning (PTP) projects were included in the 2008-2011 Pluriannual Plan. At the federal scale, the impacts of the Growth Acceleration Program (PAC) projects in the territory were systematized. The documents analyzed were the reports from the PAC of Pará, and the state reports from the PPA 2008-2011 formulated by the State Secretariat for Planning, Budget and Finance (SEPOF). The result reinforced the concentration of PPA projects 2008-2011 in the Metropolitan Region of Pará and PAC's developments were devolved from it, but were directed towards the comparative advantages of natural 
resources and the environmental and social mitigation of the impact of large infrastructure projects in the Carajás sub-region.

Keywords: PAC. Participatory Strategic Planning. Carajás. Multiannual Plan. Pará.

\section{La planificación territorial participativa (PTP) y PAC en disputa para el desarrollo de la región de integración de Carajás - Pará}

\section{Resumen}

Este artículo presenta el balance de los impactos de las políticas públicas basadas en la medición de proyectos e inversiones a escala estatal y federal, en los años 2008 a 2018, en la subregión de Carajás, en Pará. A escala estatal, se analizó si los proyectos de Planificación Territorial Participativa (PTP) se incluyeron en el Plan Plurianual 2008-2011. A escala federal, se sistematizaron los impactos de los proyectos del Programa de Aceleración del Crecimiento (PAC) en el territorio. Os documentos analisados foram os relatórios do PAC do Pará, e os relatórios estaduais do PPA 2008-2011 formulados pela Secretaria de Estado de Planejamento, Orçamento e Finanças (SEPOF). El resultado reforzó la concentración de los proyectos de PPA 2008-2011 en la Región Metropolitana de Pará y los proyectos de PAC se derivaron de él, pero se dirigieron hacia las ventajas comparativas de los recursos naturales y la mitigación ambiental y social del impacto de grandes proyectos de infraestructura en el Subregión de Carajás.

Palabras clave: PAC. Planificación Estratégica Participativa. Carajás. Plan Plurianual. Pará.

\section{Introdução}

As desigualdades regionais da Amazônia foram extensamente debatidas em formato de planos, programas e projetos: pela Superintendência do Plano de Valorização Econômica da Amazônia (SPVEA), que propôs a ocupação da terra via migração e geração de renda pela agricultura; pela Superintendência de Desenvolvimento da Amazônia (SUDAM) que balizou as suas ações pelo planejamento setorial, por intermédio dos projetos do Polamazônia e a modernização da agropecuária.

Nos anos 2000 os órgãos de planejamento estatais ressignificaram 0 diagnóstico e o prognóstico para o tratamento das desigualdades regionais da Amazônia, pela nomenclatura de heterogeneidades territoriais. A Política Nacional de Desenvolvimento Regional (PNDR) formulada em 2003 e institucionalizada em 2007, propôs a coordenação entre esta política e os planos e programas em diferentes escalas territoriais, por intermédio da coalizão entre as instâncias governamentais, com o enfoque nas especificidades dos territórios.

Sob este escopo, este artigo analisa o planejamento multiescalar proposto pela PNDR aplicado no estado do Pará, do qual pretende-se averiguar em que medidas houve diálogo entre as políticas públicas do governo federal e as do governo do Pará para a sub-região de Carajás, nos anos 2008 a 2018.

Dentre as estratégias para o planejamento regional sob o preâmbulo federativo, entre as escalas nacional e a estadual do Pará, a PNDR e o Planejamento Territorial Participativo (PTP) foram as experiências que se aproximaram da efetivação da implementação de uma política de desenvolvimento territorial que se adequassem às diretrizes de participação social, na deliberação para a formulação da agenda de políticas públicas, descentralização administrativa e projetos para a dinâmica produtiva fomentados de acordo com às especificidades territoriais das sub-regiões do Pará. 
A escolha pela sub-região de Carajás ${ }^{1}$ é devido ao seu posicionamento na regionalização produtiva do Pará, com destaque para a produção agropecuária e extração de minérios na configuração que assumiu entre as escalas local com o global, ajustada à lógica de inserção no comércio internacional do Brasil por intermédio de exportação de commodities, tendo limitada aderência à geração de efeitos para frente e inclusão social.

Em 2018, segundo os dados do Ministério da Economia, Indústria, Comércio Exterior e Serviços (MDIC), as exportações de Parauapebas representaram 40\% do volume total do estado do Pará, no qual a sua pauta de produtos exportados foi composta por $98 \%$ de minério de ferro. As exportações de Marabá representaram 10,2\% do volume total do estado do Pará e o minério de cobre representou $90 \%$ dos produtos da sua pauta exportadora. O município de Canaã dos Carajás contribuiu com $21,9 \%$ das exportações do estado do Pará, e o principal produto exportado foi o minério de ferro, que representa $92 \%$ da sua pauta exportadora ${ }^{2}$.

Porém, subjacente a pujante participação nas exportações de minério da sub-região de Carajás, há desigualdades sociais latentes em seus municípios, que são replicados para o prisma das heterogeneidades territoriais. Este artigo priorizou a análise de duas experiências de políticas de desenvolvimento que possuem metodologias diferentes para o desenvolvimento territorial. A primeira experiência é a do PTP que pode ser posicionado como mais aderente às diretrizes da PNDR. A segunda experiência é o Programa de Aceleração do Crescimento (PAC) que gerou descentralização dos investimentos do governo federal nos municípios do Pará.

O recorte temporal da análise das experiências supracitadas, de propostas de projeto para o desenvolvimento para o Pará, foi o período de 2008 a 2018 e objetivou realizar um balanço em dois movimentos. $O$ primeiro foi interpelar em que medida houve a inserção de projetos propostos pelo PTP no Plano Plurianual 2008-2011 para a sub-região de Carajás. O segundo foi averiguar o impacto dos empreendimentos do PAC nos municípios da sub-região de Carajás.

Os documentos do governo federal analisados foram os relatórios do Programa de Aceleração do Crescimento Econômico (PAC) do Pará: Programa de Aceleração do Crescimento: Balanço 4 anos, 2007-2010 Pará; Programa de Aceleração do Crescimento: $11^{\circ}$ balanço 20112014 Pará; Programa de Aceleração do Crescimento: $7^{\circ}$ balanço 20152018 Pará. A análise foi complementada pelos relatórios formulados pela Secretaria de Estado de Planejamento, Orçamento e Finanças (SEPOF), Orientação Estratégica do Governo. Anexo, de 2010, Relatório de Avaliação do Plano Plurianual 2008-2011, Relatório de Avaliação do Plano Plurianual 2008-2011: Programa Finalístico, Relatório de Avaliação do Plano Plurianual 20082011: Programa de Política Pública, ambos de 2011.

\footnotetext{
${ }^{1}$ Esta sub-região é composta pelos municípios Bom Jesus do Tocantins, Brejo Grande do Araguaia, Canaã dos Carajás, Curionópolis, Eldorado dos Carajás, Marabá, Palestina do Pará, Parauapebas, Piçarra, São Domingos do Araguaia, São Geraldo do Araguaia e São João do Araguaia.
}

2 MDIC, Ministério da Indústria, Comércio Exterior e Serviços. Consultado em http://www.mdic.gov.br/comercio-exterior/estatisticas-de-comercio-exterior/comex-vis/framemunicipio?municipio $=1502152$ 
Este artigo está dividido em três tópicos, além desta introdução e das considerações finais. O primeiro tópico buscou apresentar as problemáticas evidenciadas na agenda de pesquisa sobre as desigualdades regionais do Brasil nos anos 2000 a 2010. O segundo tópico apresentou os projetos deliberados nas reuniões do PTP pelas sub-regiões do Pará e os projetos implementados no PPA 2008-2011. O terceiro tópico apresentou os projetos implantados pelo PAC nos municípios da sub-região de Carajás.

\section{A fragmentação produtiva e as dificuldades de implementação do planejamento multiescalar da PNDR}

Há uma importante literatura que formulou chaves interpretativas das mudanças produtivas no Brasil sob a ótica do regional, realizadas nos anos 1980 a 2000: 1) Diniz (1993) entendeu que as mudanças espaciais da atividade industrial caminharam na direção da formação de um polígono, de modo a reconcentrar a atividade produtiva em um limitado espaço composto por metrópoles no Sul e Sudeste do país; 2) Cano (2007) interpretou que alguns fatores contribuíram para frear o crescimento das regiões atrasadas no Brasil, ao mesmo tempo em que outros teriam favorecido a desconcentração da atividade produtiva; 3) Para Pacheco (1998) apesar da desaceleração do ritmo de desconcentração, pós anos 1980 , esse processo não interrompeu a atividade produtiva, mas se manifestou como o fenômeno da fragmentação econômica do Brasil; 4) Guimarães Neto (1997) afirmou que não é possível discernir se houve uma continuidade da desconcentração ou reconcentração de investimentos nas regiões brasileiras; 5) Bacelar de Araújo (2000) compactou com a tese da intensificação das heterogeneidades intra-regionais a partir dos anos 1980 e acompanhou o processo de desconcentração da expansão da agricultura e da indústria para regiões ou subregióes menos desenvolvidas ; 6) Para Becker (2010) a Amazônia foi inserida no sistema global, mobilizado pelas categorias de análise da relação capital trabalho, instituída pela produção no espaço e controlado pela hierarquização do capital e regulação dos Estados nacionais.

Nos anos 1990 a literatura referida consolidou uma importante agenda de pesquisas para o planejamento urbano e regional do Brasil. Nas décadas de 2000 a 2010, a agenda foi organizada em decorrência dos fenômenos de fragmentação produtiva espacial, heterogeneidades intra-regionais e desconcentração espúria da estrutura produtiva. De acordo com Abdal (2020) houve a formação de uma agenda de pesquisa que priorizou as consequências da fragmentação produtiva nas regiões Norte e Centro Oeste, e que apesar das suas particularidades, compartilharam características que são resultantes da posição periférica na economia nacional e do capitalismo global pela produção e extração de commodities, e instalação de grandes projetos em infraestruturas logística e energia. Essa agenda tem por objetivo mensurar os efeitos das políticas públicas de desenvolvimento, balizada pelos investimentos das escalas municipal, estadual e federal, sobre as economias dessas regiões.

As proposições de Abdal (2020) estão associadas aos fatores que compuseram o contexto socioeconômico e político do Brasil nas décadas 2000 a 
2010 para permanências do quadro de assimetrias territoriais: a) o ritmo do crescimento econômico foi mantido até 2010 pela demanda exterior por commodities agrícolas e minerais e posteriormente desacelerou; b) houve políticas com intencionalidade de desenvolvimento pelo Estado até 2010 e entre 2014 e 2016 houve redução e paralisia das ações do governo federal; c) baixa implementação e efetividade da política nacional de desenvolvimento regional (PNDR).

Nos anos 2003 a 2015, Brandão (2019) interpretou que foram determinantes os investimentos do Estado em setores prioritários da economia e redistribuição de renda com inclusão social da população. O autor identificou neste processo um padrão nas inversões públicas e privadas, que permaneceram limitadas à inércia litorânea, com exceção à alguns pontos de enclaves, resultante da expansão da produção de commodities, pela infraestrutura e pelos gastos sociais. A partir de 2015 esse padrão foi rompido, com impactos para expansão das desigualdades territoriais.

A análise de Brandão discorreu sobre cinco diferentes tipos de investimentos, baseados na metodologia de tipos ideais, que impactaram os territórios. As maiores fontes de investimentos do governo federal, nos anos 2003 a 2015, foram oriundas do Banco Nacional de Desenvolvimento Econômico e Social (BNDES) e do PAC. Os investimentos do BNDES foram direcionados com apoio de capitais privados para os setores da agroindustriais, para grandes projetos nos segmentos de plantas automobilistas, siderurgia, petróleo, naval, refinarias e extração mineral. O PAC foi responsável pelos investimentos em infraestrutura, principalmente no setor energia no interior do Brasil.

Territórios Tipo I - impactados pela força inercial dos fatores de aglomeração e de urbanização (litoral, RMs e capitais) e das vantagens locacionais produtivas da rede urbana do Sul-Sudeste; Territórios Tipo II impactados pela implantação de investimentos pontuais, com tendência a se constituírem em polos isolados ou enclaves com baixa indução do entorno e da hinterlândia; Territórios Tipo III - impactados pela demanda mundial de commodities; Territórios Tipo IV - impactados pelos investimentos realizados ou orientados pelo Estado em infraestrutura de transportes e energia etc.; Territórios Tipo $\mathrm{V}$ - impactados pelos impulsos das políticas sociais, melhorias das condições de vida e nos equipamentos sociais, ampliação do mercado interno de consumo (BRANDÃO, 2019, p. 261).

A partir da definição de Brandão (2019) sobre as tipologias de investimentos nos territórios, pode ser apontado que no Pará, na sub-região de Carajás, a dinâmica produtiva foi moldada pelas características dos territórios do tipo II, III e IV. O tipo de investimento do território II foi proveniente de grandes obras em infraestrutura e enclaves de extração de recursos naturais. O centro de decisões foi formado de forma exógena, por decisões extrarregionais, o que caracterizou polos isolados. $O$ tipo ideal de território tipo III apresentou como característica os investimentos em commodities, agrícolas, minerais, metálicas e energéticas. Possui muitas deficiências em suas relações inter-ramificações, inter-regionalidades e interurbanas. Os investimentos em territórios do tipo IV foram oriundos do Estado em infraestrutura de transportes e energia, do qual pode ser gerado externalidades e sinergias no território e estão presentes na Amazônia. 
Diante dos fenômenos oriundos das desigualdades, de assimetrias intraregionais e fragmentação produtiva dos territórios, Brandão (2008) é assertivo ao afirmar que para a compreensão do território é preciso interpelar a relação entre os processos, dinâmicas, estruturas, sujeitos e relações com a natureza polimórfico do sistema capitalista. O recurso metodológico para empreender esse estudo mobilizado por Brandão possui como base analítica a economia política e a geografia crítica, com o desafio de interpretar à ótica do subdesenvolvimento, ressignificada sob a divisão social do trabalho, como categoria balizadora das heterogeneidades, hierarquias e especializações intra e inter relacionado à escala. 0 enfoque da política econômica compreende que o movimento da acumulação de capital demonstra que a sua natureza está orientada pela multiplicação de valor e a sua aplicação é realizada de forma seletiva no território. A geografia crítica utiliza como arcabouço a compreensão da ação do capital no território, metamorfoseado em empreendimentos produtivos que determinam as hierarquias no espaço e território, cuja prioridade é a obtenção de recursos naturais em detrimento dos sujeitos sociais, o que gera movimentos de resistência, protestos e combates emancipatórios. O referido autor ressalta que as pesquisas sobre a dimensão territorial devem priorizar a identificação das relações do poder, das hierarquias e das hegemonias.

A escala na percepção do autor referido é designada como sínteses dos fenômenos sociais e é a arena política, formatada pelas coalizões de poder. A discussão da escala espacial é fundamental para diagnosticar os problemas concernentes à cada uma. O seu enfrentamento é composto pela identificação das formas de representação no território das hegemonias, poderes e hierarquias como mediação para a acumulação de capital. A reversão do processo de tomadas de decisões e poder deliberadas da escala global para a local, pelos empreendimentos de acumulação de capital, requer o protagonismo de atores, agentes e classes sociais na formação de processos decisórios participativos locais para a territorialização das deliberações participativas populares (BRANDÃO, 2008).

A reprovação do Fundo Nacional de Desenvolvimento Regional (FNDR) prejudicou a implementação da proposta da PNDR. Em 2008, o secretário Bernand Appy, de Política Econômica do Ministério da Fazenda, foi o responsável pela apresentação da proposta da FNDR para a Comissão Especial da Câmara dos Deputados, incluída na PEC número 233/2008, da reforma tributária. A argumentação da referida comissão para reprovação da FNDR era subsidiar por meio do financiamento de projetos do PAC o planejamento regional, ao invés da aprovação de recursos específicos da FNDR para a PNDR. Porém, a regionalização dos recursos financeiros do PAC com objetivo do planejamento regional divergiu da política de zoneamento regional da PNDR, que exerceria outras funções, enquanto o PAC foi direcionado para construção de grandes projetos (BRASIL, 2008).

Segundo Alves e Neto (2014) alguns determinantes enfraqueceram a PNDR para a sua implementação. O primeiro refere-se à ausência do FNDR, e os Fundos Constitucionais e de Desenvolvimento foram limitadas ao campo de ação do setor privado, do qual atendeu aos interesses dos setores produtivos. Em segundo, a guerra fiscal é objeto de desinteresse na ação conjunta entre as unidades federativas e a união, desarticulou o diálogo federativo em torno do consenso sobre o papel da PNDR para o desenvolvimento regional. E, em terceiro, as políticas 
públicas no Brasil são excessivamente setoriais e há dificuldades para o exercício do planejamento de longo prazo, há descoordenação entre os órgãos de planejamento do Brasil.

A proposta de planejamento multiescalar da PNDR para Amazônia combinaria o Plano Amazônia Sustentável (PAS) na escala macrorregional, os planos de desenvolvimento regionais sustentáveis (PDRSs), na escala sub-regional, e a adesão do governo estadual do Pará aos seus eixos temáticos, o que aproximaria as escalas de planejamento, do governo federal ao estadual. O enfoque da PNDR nas microrregiões (MRGs) influenciou a proposta do PTP que articularia por meio do PPA 2008 - 2011 do Pará, a participação da população na formulação da agenda de políticas públicas para 0 tratamento das especificidades das vulnerabilidades socioeconômicas dos territórios para o desenvolvimento regional.

\section{Programas em disputa para o desenvolvimento do Pará: o Planejamento Territorial Participativo e o PPA 2008-2011}

O Plano Plurianual 2008-2011 do Pará, do governo Ana Júlia Carepa, adotou a regionalização das sub-regiões do Pará, denominada de regiões de integração ${ }^{3}$, divididas em 12: Araguaia, Baixo Amazonas, Carajás, Guamá, Lago de Tucuruí, Marajó, Metropolitana, Rio Caeté, Rio Capim, Tapajós, Tocantins e Xingu. A metodologia do Planejamento Territorial Participativo (PTP) foi incorporada ao PPA 2008-2011, e elegida como fundamental para a concepção do desenvolvimento, balizada pela diversidade produtiva territorial, pela atuação do Estado por intermédio de políticas públicas para a melhoria de renda, bem-estar social, desenvolvimento tecnológico, inclusão social e uso sustentável dos recursos naturais.

O PPA 2008-2011 do Pará foi dimensionado por três macro objetivos, divididos em Qualidade de Vida Todas e Todos, Inovação para o Desenvolvimento, e Gestão Democrática e Descentralizada. Os eixos estratégicos finalísticos desses objetivos foram organizados em dimensões compostos por projetos: dimensão social; dimensão ambiental; dimensão cultural; dimensão territorial; dimensão democrática; dimensão econômica (SEPOF, 2012).

O financiamento dos recursos para a implementação dos projetos do PPA 2008-2011 foi dividido em diferentes fontes: a) gerado por receitas próprias e das constitucionalmente transferidas da União para a unidades federativas; b) transferência da União via PAC social em projetos nas áreas de habitação, saneamento, assistência e transportes; c) operações de créditos advindos do Banco de Desenvolvimento Econômico e Social (BNDES) para rodovias e parques tecnológicos; d) Banco Internacional para Reconstrução e Desenvolvimento (BIRD) e Banco Interamericano de Desenvolvimento (BID) (SEPOF, 2012).

O objetivo do PTP foi instituir a descentralização administrativa e o empoderamento dos sujeitos com a sua participação na formulação de projetos

\footnotetext{
${ }^{3}$ A regionalização foi realizada pelos estudos do Instituto de Desenvolvimento Econômico e Social do Estado do Pará (IDESP), de 1998.
} 
para o desenvolvimento socioeconômico e cultural. A organização do PTP foi realizada em três etapas. A primeira nos meses de abril e maio de $2007 \mathrm{com}$ a participação de 41.468 pessoas nas 12 plenárias públicas. Em cada plenária as demandas da sociedade civil foram organizadas como macro objetivos de ação governamental para constituir na matriz do PPA. A segunda foi realizada em julho por meio da realização de 143 assembléias públicas municipais (APMS) em todos os municípios do Pará. O objetivo foi a escolha de representantes, conselheiros, que iriam compor nos Conselhos Regionais. A terceira foi realizada em agosto com a instalação e reuniões dos Conselhos Regionais e do Conselho Estadual do PTP. Esses conselhos foram direcionados para deliberação sobre as necessidades dos municípios e contribuição do plano de desenvolvimento regional (SEPOF, 2011a).

O resultado das APMs foi a formulação de 429 ações deliberadas nas audiências locais, tendo prioridade a escolha dos conselheiros(as) para representação do município nos Conselhos Regionais. Na terceira etapa do PTP a função dos Conselhos Regionais e do Conselho Estadual do PTP foi organizar deliberativamente os Planos de Desenvolvimento Regional e o Plano de Desenvolvimento do Estado (COSTA, 2011).

Quadro 1 - Projetos do PTP para Região de Integração Carajás do Pará 2008-2011

\begin{tabular}{|c|c|c|c|}
\hline & Eixo Dimensão Social & \begin{tabular}{l}
\multicolumn{1}{c}{ Eixo } \\
Dimensão \\
Socioeconômico
\end{tabular} & $\begin{array}{c}\text { Eixo } \\
\text { Infraestrutura }\end{array}$ \\
\hline$\frac{\frac{n}{\pi}}{\frac{\pi}{\pi}}$ & $\begin{array}{l}\text { Ampliação } \\
\text { equipamentos dos hospitais } \\
\text { municipais e os regionais; } \\
\text { Educação ensino médio com } \\
\text { tempo integral; Implantação } \\
\text { de núcleos universitários da } \\
\text { UEPA. }\end{array}$ & $\begin{array}{l}\text { Fortalecime } \\
\text { nto da agricultura } \\
\text { familiar; Assistência } \\
\text { técnica; Aquisição } \\
\text { de equipamentos } \\
\text { agrícolas. }\end{array}$ & $\begin{array}{l}\text { Implantação } \\
\text { estradas e construção de } \\
\text { pontes Abastecimento d'água } \\
\text { e esgotamento sanitário; } \\
\text { Eletrificação rural; Construção } \\
\text { de casas populares. }\end{array}$ \\
\hline
\end{tabular}

Fonte: SEPOF, 2010. Elaborado pelo autor.

As demandas da população das regiões de integração foram organizadas em temas dentro dos eixos, nos quais foram inseridas propostas para programas e projetos do governo do Pará. Mediante a apresentação das propostas do PTP para a região de integração do Carajás foi analisado a distribuição de recursos financeiros pelas dimensões do PPA e pelas regiões de integração.

A dimensão da Política Social do PPA 2008-2011 foi contemplada como a que recebeu maior porcentagem dos recursos financeiros. $O$ seu programa Resolutividade na Saúde recebeu $\mathrm{R} \$ 1,790,00$ bilhão, seguido pelo programa Segurança para Todos e Todas com $\mathrm{R} \$$ 537,98 milhões, e em terceiro o programa Universidade Pública com Qualidade com $\mathrm{R} \$ 337,3$ milhões. A segunda colocada entre as dimensões foi a Política de Infraestrutura, dentre os seus programas que receberam maiores investimentos destacaram-se Água para Todos, com R\$537,0 milhões, seguido pelo programa Habita Melhor, com R\$304,8 milhões (SEPOF, 2012).

A figura 1 apresenta a distribuição de recursos financeiros do PPA 2008-2011 por região de integração do Pará. A avaliação dos dados apresenta polarização dos recursos financeiros alocados nas dimensões política social e políticas de 
desenvolvimento e meio ambiente na R.I. Metropolitana. A dimensão de infraestrutura foi a única que não concentrou recursos na R.I. Metropolitana. As sub-regiões beneficiadas com o recurso financeiro da dimensão da política de infraestrutura foram o Xingu, Lagoa do Tucuruí e Baixo Amazonas.

Os projetos implementados na dimensão de infraestrutura foram a Usina Hidrelétrica Belo Monte com 5.681 MW - 1a Etapa - PAC, no valor de R\$ 2.200.000.000 bilhões, no Xingu, o Sistema de Transmissão Tucuruí - Manaus (500 Kv - $1472 \mathrm{Km}$ ) - PAC, no valor de R\$3.000.000.000 bilhões, na Lagoa Tucuruí, e a construção do Trecho Rodoviário - Divisa MT / PA - Santarém na BR 163 - PAC, no valor de R\$1.105.150.641 bilhão, no Baixo Amazonas.

Figura 1 - Distribuição de recursos financeiros por Região de Integração do PPA 2008-2011 (R\$ milhões)

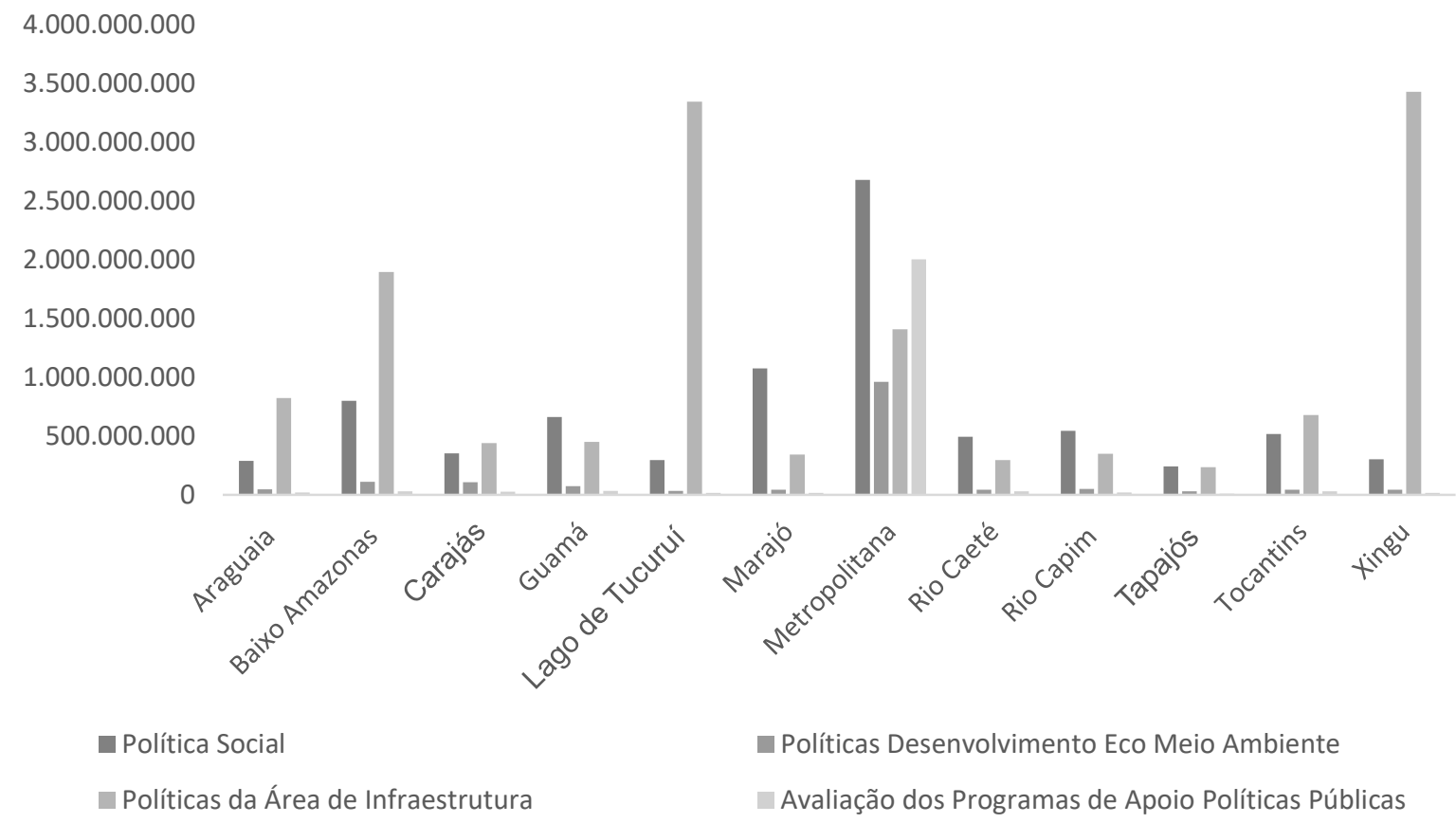

Fonte: SEPOF, 2011a; SEPOF, 2011b. Elaborado pelo autor.

No PPA 2008-2011, apesar da dimensão Política Social possuir o maior orçamento e concentrar os seus recursos financeiros na R.I. Metropolitana, 0 destaque foram os recursos provenientes do PAC para a SEPOF do Pará, para a implementação dos empreendimentos referidos em Xingu, Lagoa de Tucuruí e no Baixo Amazonas.

No quadro 2 foram apresentados os projetos demandados pela população, a partir das plenárias realizadas pelo governo estadual nos municípios. No total de 429 ações inicialmente propostas pelos resultados das plenárias populares do PTP, somente 46 projetos foram incorporados no PPA 2008-2011.

Quadro 2 - Projetos do PTP inseridos no PPA 2008-2011

\begin{tabular}{|c|c|}
\hline PA & Projetos PTP \\
\hline \multirow{3}{*}{ 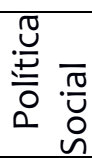 } & Produção da Programação de Telecomunicação \\
\hline & Realização de Eventos Culturais \\
\hline & Ampliação de Unidades Escolares \\
\hline
\end{tabular}




\begin{tabular}{|c|c|}
\hline & Construção de Unidades Escolares \\
\hline & Implementação da Educação Profissional \\
\hline & Implementação da Formação Digital nas Escolas Públicas \\
\hline & Implementação de Espaços Culturais de Interesse à Preservação \\
\hline & Implementação de Ações de Média e Alta Complexidade em Saúde \\
\hline & Ampliação da Capacidade Operacional dos Órgãos do SESP \\
\hline & Ampliação de Unidades e Campi Universitários \\
\hline & Construção de Campi Universitários \\
\hline \multirow{19}{*}{ 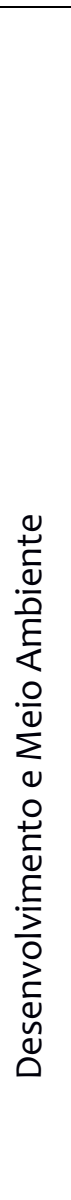 } & $\begin{array}{l}\text { Implantação/adequação da Infraestrutura de Produção, } \\
\text { Armazenamento e Comercialização do Pescado no Estado do Pará }\end{array}$ \\
\hline & Implementação de Ações do Fundo do Desenvolvimento do Estado - FDE \\
\hline & $\begin{array}{l}\text { Apoio à Gestão da Política e do Programa de Assistência Técnica e Extensão Rural } \\
\text { Pública - PROGATER }\end{array}$ \\
\hline & Apoio à Organização da Produção e Estratégia de Comercialização e Mercado \\
\hline & Apoio ao Desenvolvimento dos Territórios Rurais \\
\hline & $\begin{array}{l}\text { Assistência Técnica, Extensão Rural e Pesquisa, com Ênfase à Organização Social e } \\
\text { Gestão Ambiental }\end{array}$ \\
\hline & $\begin{array}{l}\text { Assistência Técnica, Extensão Rural e Pesquisa, em Apoio à Cadeia Produtiva } \\
\text { Sustentável de Origem Vegetal e Animal }\end{array}$ \\
\hline & Descentralização das Ações de Comercialização de Produtos Agropecuários \\
\hline & $\begin{array}{l}\text { Fomento a Floricultura, Olericultura, Plantas Medicinais e Aromáticas e à Produção } \\
\text { Orgânica }\end{array}$ \\
\hline & Fomento à Produção de Alimentos Básicos \\
\hline & Fomento à Produção de Pequenos e Médios Animais \\
\hline & $\begin{array}{l}\text { Realização de Ações de ATER e Pesquisa, em Apoio a Programas de Combate à } \\
\text { Pobreza no Meio Rural }\end{array}$ \\
\hline & Apoio à Modernização da Pecuária Bovina e Bubalina de Corte e de Leite \\
\hline & Fomento à Fruticultura \\
\hline & Apoio ao Processo de Regularização Fundiária em Área Urbana \\
\hline & Implementação da Política Estadual de Recursos Hídricos \\
\hline & Implementações de Ações de Regularização Fundiária \\
\hline & Apoio ao Desenvolvimento das Atividades Produtivas \\
\hline & Fomento à Diversificação dos Segmentos Turísticos Paraense \\
\hline \multirow{16}{*}{ 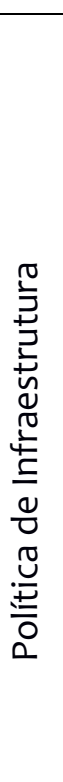 } & Conclusão das Obras de Saneamento do Projeto Alvorada \\
\hline & Implantação, Ampliação e Melhoria de Sistema de Abastecimento de Água \\
\hline & Conservação de Rodovias Estaduais \\
\hline & Construção da Infraestrutura Aeroviária \\
\hline & Desassoreamento de Pequenos Rios, Furos e Igarapés \\
\hline & Implantação de Rodovias Estaduais \\
\hline & Manutenção, Recuperação e Abertura de Vicinais \\
\hline & Pavimentação e Restauração de Rodovias Estaduais \\
\hline & Restauração de Obras D’́ Artes Especiais \\
\hline & Capacitação de Agentes Locais para o Desenvolvimento Municipal - PARÁ URBE \\
\hline & Investimentos para o Desenvolvimento Municipal - PARÁ URBE \\
\hline & Universalização de Energia Elétrica - Parceria Estado/União/Iniciativa Privada \\
\hline & Construção de Espaços de Esporte e Lazer \\
\hline & Construção de Habitação de Interesse Social \\
\hline & Saneamento Integrado da Bacia do Tucunduba / 20 e 30 Etapas - PAC \\
\hline & Urbanização, Regularização e Integração de Assentamentos Precários - FNHIS \\
\hline
\end{tabular}

Fonte: SEPOF, 2011a; SEPOF, 2011b. Elaborado pelo autor. 
$\mathrm{Na}$ figura 2 é apresentada a distribuição dos recursos financeiros dos projetos do PTP, que foram inseridos no PPA, de acordo com as regiões de integração do Pará. Na dimensão da política social, os projetos em destaque do PTP na região de integração Metropolitana foram o projeto de Implementação de Ações de Média e Alta Complexidade em Saúde, custeado em R\$ 640.770.093 milhões, acompanhado pelo projeto Ampliação da Capacidade Operacional dos Órgãos do SESP, no valor de $\mathrm{R} \$ 111.167 .304$ milhões, somando no total para esta dimensão na Metropolitana, em R\$ 868.457.489 milhões. Na dimensão da política infraestrutura, os projetos em destaque do PTP para a região de integração Araguaia foram os projetos Pavimentação e Restauração de Rodovias Estaduais, no valor de R\$ 300.511 .926 milhões e Universalização de Energia Elétrica, no valor de $\mathrm{R} \$$ 198.096.463 milhões, de um total nos projetos de política de infraestrutura para Araguaia de $\mathrm{R} \$ 642.541 .291$ milhões.

Figura 2 - Distribuição de recursos financeiros por Projetos do PTP incluídos no PPA 2008-2011 (R\$ milhões)

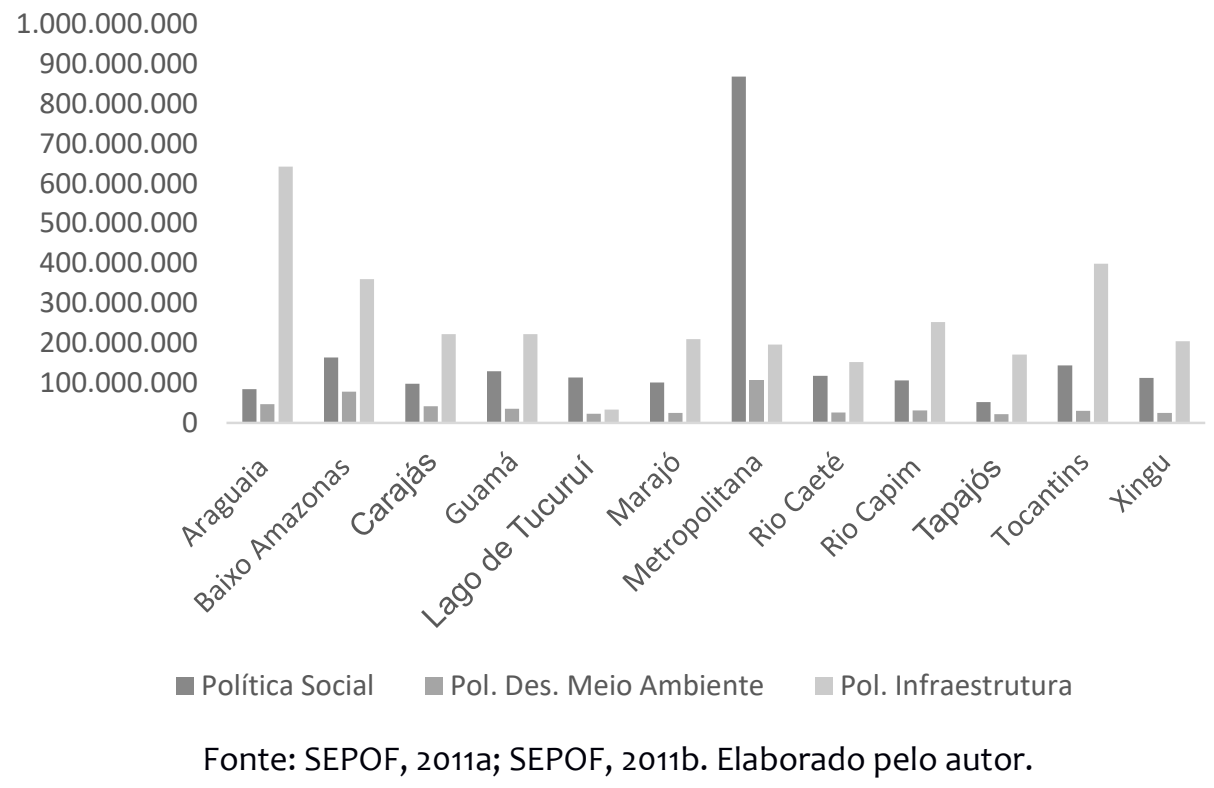

Para Lima (2010) a reprovação do projeto de lei que propunha a criação da estrutura administrativa do PTP e a falta de coalizão política entre o governo estadual e os deputados estaduais, prejudicaram a implementação de todos projetos propostos pela população e friccionou as relações políticas entre o poder Executivo e o Legislativo.

havia uma constante tensão em torno de ações que pudessem atingir, em maior quantidade de recursos, as bases dos deputados, sob pena de não contribuir para a aprovação de projetos de lei do executivo, o que torna o processo de discussão do PPA destituído de estratégias mais amplas; a inclusão de emendas parlamentares na execução orçamentária do governo não era feita por dentro da proposta do PPA, o que torna os investimentos fragmentados e desarticulados; o desequilíbrio de forças entre os representantes regionais passaria para a distribuição de recursos do PPA, acirrando a disputa política em torno do tratamento da assimetria regional do Estado; o aumento dos recursos de um programa em 
detrimento de outro não era aceito como parte das negociações de aprovação de emendas; as discussões foram centradas em proposições sobre a distribuição de metas físicas e financeiras dentro de um mesmo programa (LIMA, 2010, p. 182-183).

Na figura 3 é possível comparar os valores empregados para os projetos que constam no PPA em relação aos que foram aprovados do PTP. Há forte descompasso com as propostas iniciais do PTP, nas instâncias das plenárias populares realizadas nas regiões de integração do Pará. Há permanência da concentração de recursos dos projetos do PPA e do PTP na R.I. Metropolitana, somente os projetos em energia da carteira de investimentos do PAC foram descentralizados da área metropolitana.

Figura 3 - Comparação dos valores dos projetos do PPA em relação aos aprovados do PTP 2008-2011 (R\$ milhões)

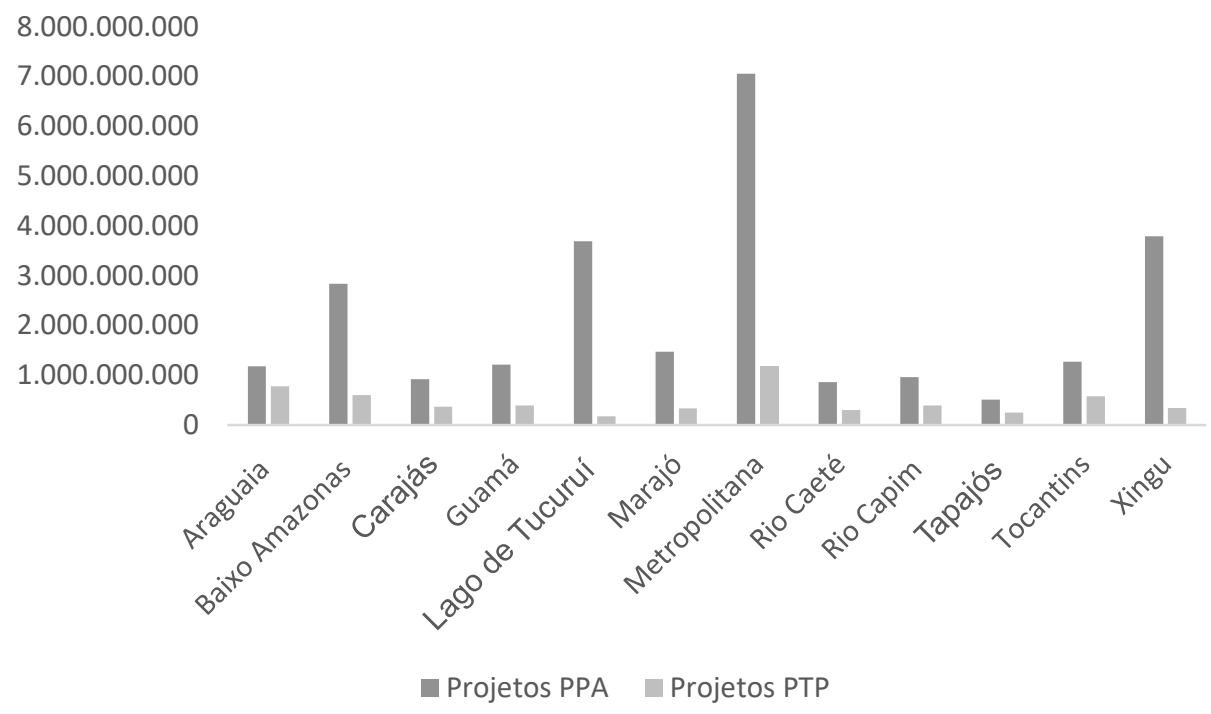

Fonte: SEPOF, 2011a; SEPOF, 2011b. Elaborado pelo autor.

Os projetos do PTP financiados pelo governo estadual para a região de integração do Carajás segundo as dimensões dos programas apresentou a política de infraestrutura com a maior parcela de investimentos recepcionados pelos municípios, R\$217.100.497 milhões, com ênfase em projetos de saneamento básico e infraestrutura urbana.

Figura 4 - Divisão de recursos financeiros pelos projetos aprovados do PTP no PPA 2008-2011 na Região Integração de Carajás (R\$ milhões) 


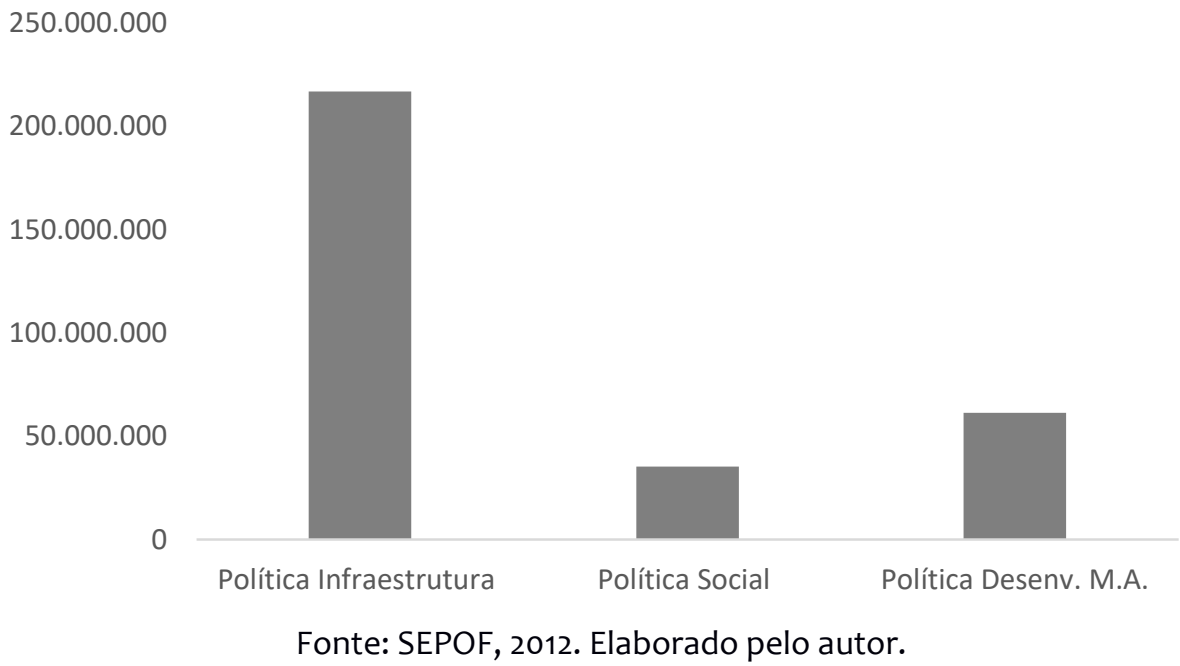

Para Lima (2010) a relação federativa exercida entre a união e a unidade federativa, do Pará, foi regida por desencontros no âmbito da implementação do planejamento entre essas instâncias. Houve maior aproximação das relações institucionais entre as municipalidades e as ações do PAC do governo federal, com financiamento de projetos em infraestrutura.

O PAC foi inserido dentro da agenda de planos e programas no Pará com ênfase em projetos infraestrutura energética e logística, posicionado com maior prioridade do que as propostas advindas das plenárias realizadas pelo PTP. Os projetos do PTP perderam espaço na agenda da gestão do PPA, o que consolidou uma aproximação via relações institucionais entre o governo federal e os municípios paraenses, em um modelo semelhante ao top-down de políticas públicas, proporcionada pela marginalização das tomadas de decisão geradas pela participação popular nas deliberações acerca dos empreendimentos do PAC nas sub-regiões do Pará.

\section{Descentralização e impactos dos empreendimentos do PAC na R.I. Carajás}

Na avaliação de Gomide e Pereira a relação institucional estabelecida entre o PAC e os municípios foi limitada a atuação em desapropriações necessárias ou para solucionar problemas durante a implementação de empreendimentos. O PAC alocou $62 \%$ dos recursos do orçamento fiscal em municípios, em projetos em infraestrutura urbana e logística. Em regiões periféricas a sua capacidade administrativa influenciou negativamente a efetividade da implementação dos empreendimentos de infraestrutura. Neste processo, a participação social no ciclo de políticas públicas foi contingenciada à momentos específicos, como o setor de proteção e promoção social que acionou os conselhos gestores e as conferências nacionais, a área de infraestrutura utilizada como canal de diálogo com a sociedade civil, as audiências públicas, no processo de licenciamento ambiental. Os autores supracitados apontam que devido o baixo envolvimento nos processos decisórios dos entes federados das grandes obras do programa, denominaram como projetos territorialmente cegos, em que estados e municípios são vistos como meros repositórios de investimentos (GOMIDE E PEREIRA, 2018, P. 17). 
Lotta e Favareto analisaram seis projetos do PAC e constataram que algumas variáveis que configuraram o fenômeno de projetos territorialmente cegos foram reincidentes. Os investimentos em infraestrutura possuem relação com os territórios de forma pontual, ou seja, são espaços que recebem investimentos. A deliberação entre união e município, local da obra, é de forma compensatória ou por mitigação de impactos negativos causados pela instalação de obras em infraestrutura. Portanto, a marginalização das características sociais dos territórios e a padronização no formato do projeto implementado em lugares com identidades específicos, são características comuns nos casos em estudo. É justamente essa maior ou menor aderência e coerência entre o projeto da obra e o tecido social e econômico dos territórios o que desencadeia processos de contestação, que muitas vezes acarretam atrasos e aumentos de custos (LOTTA e FAVARETO, 2018, p. 251).

O Estado assumiu protagonismo em programas de infraestrutura, especialmente em obras de energia. A justificativa para escolha das localidades para as obras do PAC adveio de vantagens competitivas naturais, ligadas à localização mineral e especialmente geográfica, de modo que não houve espaço para negociação com os entes federativos sobre sua realização. Coube aos municípios papéis específicos, de forma subalterna em processos decisórios de implementação das obras do PAC nos territórios sob a sua gestão local (LOTTA e FAVARETO, 2018).

No Pará, os empreendimentos formulados pelo PAC não apresentaram critérios de regionalização dos investimentos e não dialogaram com as secretarias dos ministérios responsáveis pela territorialização do planejamento. O PAC não considerou o enfoque multiescalar na formulação de políticas públicas e as especificidades territoriais priorizadas pela PNDR, optou em dar suporte logístico para a intensificação da especialização produtiva em commodities, na produção agropecuária e extração mineral, oriunda principalmente do Sul do Pará (LEITÃO, 2009).

No quadro 3, os investimentos realizados pelo governo federal em empreendimentos do PAC no Pará, no período 2007 a 2018, estão divididos em: primeira fase do PAC, de 2007 a 2010, em que houve dispêndio maior de recursos financeiro no eixo de infraestrutura urbana e social, com ênfase em projetos em sistema de abastecimento de água, ampliação do esgotamento sanitário, urbanização e reassentamento de famílias localizadas em beiras de córregos e áreas de risco (BRASIL-PAC, 2010).

$\mathrm{Na}$ fase 2 do PAC, de 2011 a 2014, o eixo de energia superou o de infraestrutura social e urbana na recepção de investimento do governo federal. Os principais empreendimentos implementados pelo eixo de energia no Pará foram: geração de energia elétrica, $R \$$ 19.740,10 bilhões; transmissão de energia elétrica, $R \$$ 1.115,04 bilhão; e, combustíveis renováveis, $\mathrm{R} \$ 57,44$ milhões. O projeto que recebeu maior valor foi a usina hidrelétrica de Belo Monte, R\$ 19.738,10 bilhões. Em contrapartida, no eixo Cidade Melhor, o empreendimento em saneamento foi o que maior recurso recebeu dentre os demais projetos, $\mathrm{R} \$ 337,68$ milhões. (BRASIL-PAC, 2015).

Nos anos 2015 a 2018, os recursos financeiros do PAC recuaram nos eixos energético e social e urbana, em comparação aos dos anos anteriores. Entretanto, o eixo energético continuou em primeiro lugar na recepção de investimentos do governo federal, com $\mathrm{R} \$ \mathbf{8 . 5 3 6 , 6 4}$ bilhões, seguido pelo de logística, o único dos 
eixos que não regrediu em termos de valores alocados pelo governo federal em relação aos anos anteriores, com $\mathrm{R} \$ 4.358,40$ bilhões. O empreendimento em geração de energia elétrica que obteve maior recurso foi a hidrelétrica de Belo Monte, com R\$8.504,02 bilhões. (BRASIL-PAC, 2018).

Quadro 3 - Investimento em Empreendimentos Exclusivos PAC no Pará 2007 - 2018

\begin{tabular}{|c|c|c|c|c|c|}
\hline $\begin{array}{l}\text { PAC } 2007 \\
\text { a } 2010- \\
\text { Eixos }\end{array}$ & $\begin{array}{l}\text { Empreendimento } \\
\text { Exclusivo 2007- } \\
\text { 2010(R\$ milhões) }\end{array}$ & $\begin{array}{l}\text { PAC } 22011 \text { a } \\
2014 \text { - Eixos }\end{array}$ & $\begin{array}{l}\text { Empreendimento } \\
\text { Exclusivo 2011- } \\
2014 \text { (R\$ } \\
\text { milhões) }\end{array}$ & $\begin{array}{c}\text { PAC } 2015 a \\
2018\end{array}$ & $\begin{array}{c}\text { Empreen } \\
\text { dimento } \\
\text { Exclusivo } \\
2015-2018 \\
\text { (R\$ } \\
\text { milhões) }\end{array}$ \\
\hline Logística & $2.688,1$ & Transportes & $3.293,49$ & Logística & $4.358,40$ \\
\hline Energética & 173,3 & Energia & $20.912,58$ & Energética & $8.536,64$ \\
\hline \multirow{4}{*}{$\begin{array}{l}\text { Social } \\
\text { Urbana }\end{array}$} & \multirow{4}{*}{$6.816,3$} & $\begin{array}{c}\text { Cidade } \\
\text { Melhor** }\end{array}$ & 789,19 & \multirow{4}{*}{$\begin{array}{l}\text { Social } \\
\text { Urbana }\end{array}$} & \multirow{4}{*}{$2.701,88$} \\
\hline & & $\begin{array}{l}\text { Comunidade } \\
\text { Cidadã }\end{array}$ & 549,80 & & \\
\hline & & MCMV & $8.847,90$ & & \\
\hline & & $\begin{array}{l}\text { Água e Luz } \\
\text { para Todos }\end{array}$ & $2.551,32$ & & \\
\hline Total & $9.677,9$ & Total & $36.944,27$ & Total & $15.596,92$ \\
\hline
\end{tabular}

Fonte: BRASIL 2010, BRASIL 2015 e BRASIL 2018. Elaborado pelo autor.

O outro filtro de análise aplicado para analisar os investimentos do PAC na região de integração dos Carajás, foi a divisão por eixos ${ }^{4}$, aplicado nos municípios da região de integração dos Carajás. Dois empreendimentos do PAC impactaram os doze municípios da sub-região de Carajás, no qual permitiu organizá-los em dois grupos. O primeiro grupo foi composto pelos municípios Bom Jesus do Tocantins, Brejo Grande do Araguaia, Marabá, Palestina do Pará, São João do Araguaia, balizados pela recepção de recursos do PAC por mitigação de danos sociais e ambientais, pelo projeto Execução de Ações de Caráter Social, decorrentes das Eclusas de Tucuruí, no valor de R\$ 31.020 milhões de reais, com exceção de Palestina (Consultado em: http://pac.gov.br/obra/15399).

O segundo empreendimento dentro deste quadrante de impactos territoriais negativos foi o de Aproveitamento Hidrelétrico de Marabá, no valor de $\mathrm{R} \$ 80.000$ milhões (Consultado em: http://pac.gov.br/obra/8417).

O segundo grupo de municípios foi balizado pelos investimentos do PAC no eixo de infraestrutura social urbana, no qual foram polarizados em Marabá, representados por R\$ 449.904 milhões. Acompanhado por Canaã dos Carajás, Curianópolis, Eldorado do Carajás, Parauapebas, Piçarra, São Domingos do Araguaia e São Geraldo do Araguaia, do qual compartilharam a recepção de recursos do eixo infraestrutura urbano e social.

Figura 5 - Investimentos por eixos do PAC nos municípios sub-região Carajás - PA

(em R\$ mil)

\footnotetext{
${ }^{4}$ Considerou a última atualização dos dados pelo site das obras do PAC, junho de 2018. Consultado no endereço eletrônico http://pac.gov.br/estado/pa
} 


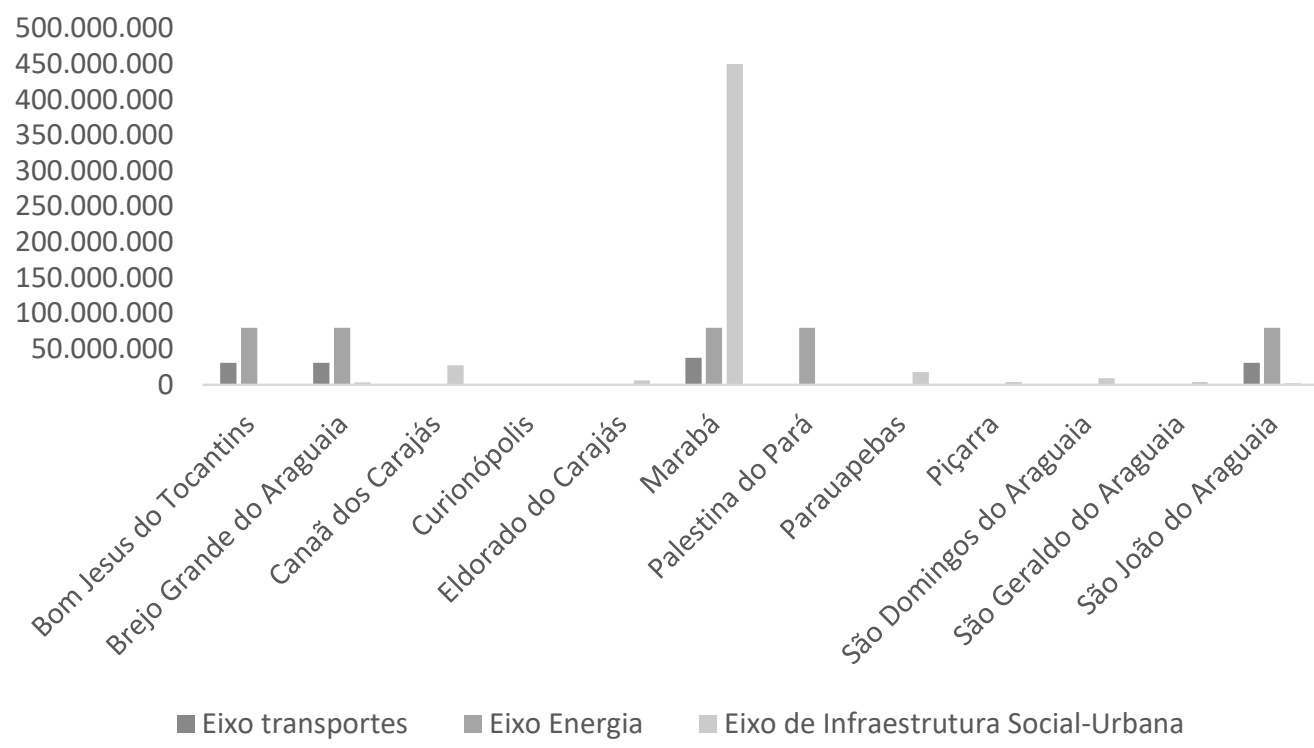

Fonte: Elaborado pelo autor. Consultado no site http://pac.gov.br/estado/pa

A síntese da avaliação do valor relativo de investimentos em projetos realizados pelo PAC por municípios na região de integração dos Carajás foi formada por um cinturão composto por Marabá, que liderou a recepção com R\$ 568.055.075 milhões, seguido pelos municípios de Brejo Grande do Araguaia com R\$ 114.486.787 milhões, São João do Araguaia com R\$113.598.995 milhões, Bom Jesus do Tocantins com R\$1 112.075.899 milhões e Palestina do Pará com R\$ 80.511.646 milhões.

Mapa 1 - Investimentos do PAC em projetos nos municípios da sub-região Carajás (em \%)

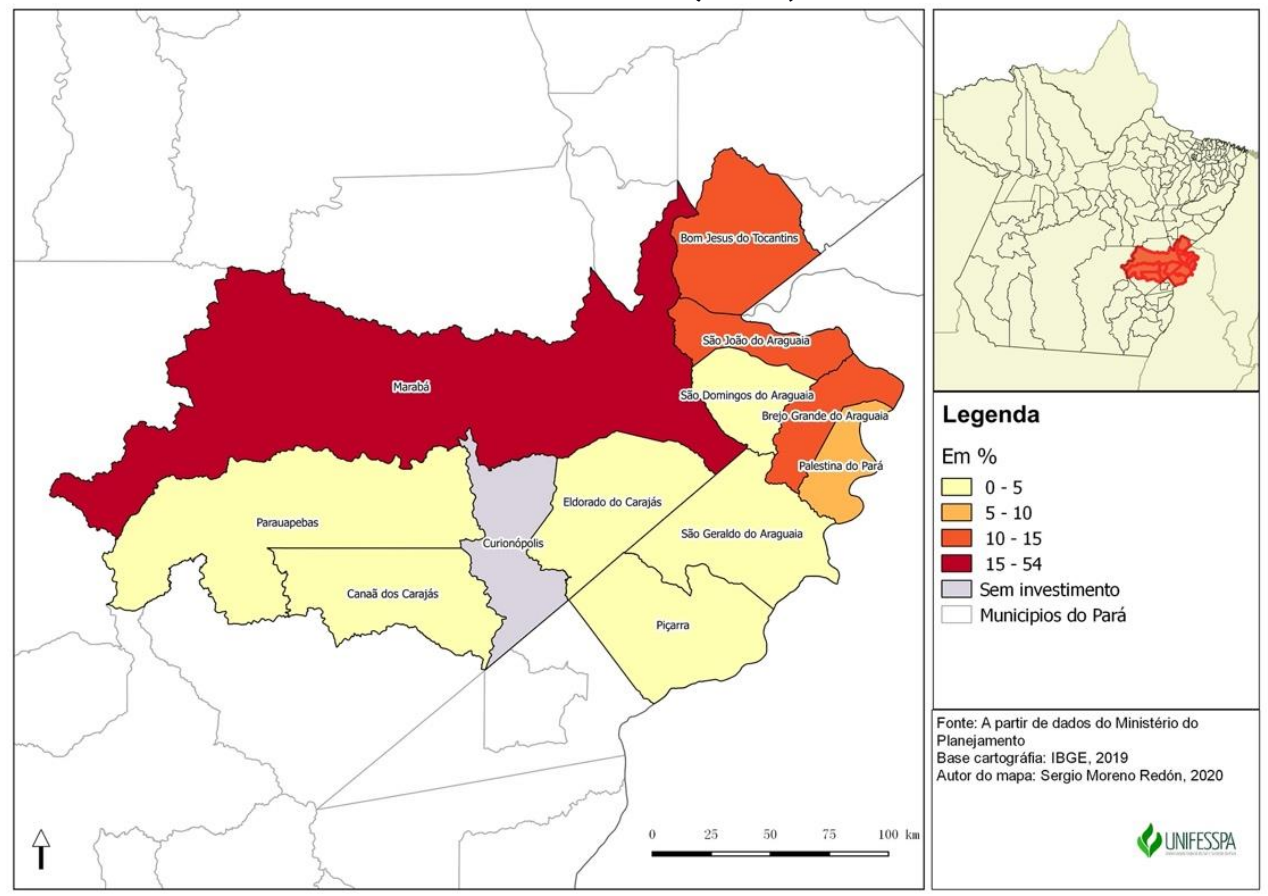

Fonte: PAC. Consultado no site pac.gov.br/obra. Dados organizados pelo autor.

Segundo Leitão (2009) a realização dos projetos em infraestrutura urbana e social do PAC para o Pará obedeceu aos seguintes critérios de escolha. Em primeiro 
lugar houve prioridade para os investimentos na região metropolitana e em municípios com população superior a 150 mil habitantes. Em segundo lugar os projetos de abastecimento de água e esgotamento sanitário foram direcionados para municípios com população menor a 150 mil habitantes. Posteriormente, os projetos referidos foram dedicados aos municípios com população inferior a 50 mil habitantes, áreas rurais e comunidades indígenas. E, finalmente, em quarto lugar priorizou-se os projetos habitacionais em comunidades indígenas e quilombolas.

Apesar desta inferência em relação aos recursos aplicados pelo PAC nos munícipios da R.I. Carajás, a ausência de processos deliberativos entre as instâncias de gestão com a participação social, resultou em repasses do governo federal para ser executado pelo governo municipal ou estavam associados à mitigação de danos ambientais e sociais provocados pela construção de obras de infraestrutura energética.

\section{Considerações Finais}

A agenda de pesquisa apresentada por Abdal (2020) aponta que o adensamento produtivo em commodities e extração de minério nas regiões Norte e Centro Oeste, reverberaram na fragmentação produtiva espacial e principalmente na fratura do diálogo federativo na busca de alinhamento do planejamento multiescalar entre as instâncias governamentais nas escalas municipal, estadual e federal.

A PNDR propôs ações descentralizadas, a participação popular nas tomadas de decisão sobre a formação de agenda de políticas públicas para o território e fortalecimento institucional dos municípios, permitindo o diálogo entre as instâncias do governo federal, do estadual. A recusa da proposta do FNDR e a incorporação do PAC como fonte de recursos orçamentários para implementação de empreendimentos regionais, como os projetos da Usina Hidrelétrica Belo Monte no Xingu, Implantação de Sistema de Transmissão Tucuruí - Manaus na Lagoa de Tucuruí e Trecho Rodoviário - Divisa MT / PA - Santarém na BR 163 no Baixo Amazonas, gerou uma série de convulsões no tecido organizacional do diálogo federativo entre atores sociais e as instituições públicas, de modo a esvaziar a agenda que correspondesse às demandas propostas pela população.

A denominação de Gomide e Pereira (2016) para os projetos do PAC como territorialmente cegos, marginalizou a participação de atores locais no planejamento e impulsionou a (re)centralização de investimentos nos grandes empreendimentos. Leitão (2009) complementa que a seleção espacial dos empreendimentos do PAC obedeceu aos interesses das empresas transnacionais combinadas ao capital nacional, por intermédio da instalação de corredores multimodais especializados no escoamento da produção do agronegócio e extração de minérios, e atendimento aos setores eletrointensivos a preços subsidiados no Pará.

A Secretaria de Planejamento, Orçamento e Finanças (SEPOF) polarizou os programas do PPA 2008-2011 na R.I. Metropolitana, principalmente nos programas da dimensão da Política Social, R\$ 2.676.779.765 bilhões. As exceções foram os projetos financiados pelo PAC, supracitados, nas regiões de integração do Xingu, de Tucuruí e no Baixo Amazonas. Portanto, a descentralização de investimentos da região Metropolitana ocorreu fortemente determinada por conta das vantagens 
competitivas do território determinadas pelos recursos naturais para instalação do empreendimento. A participação das instâncias do governo municipal e atores sociais foram relacionadas a mitigação dos prejuízos sócio ambientais causados pelos referidos empreendimentos.

No balanço do PAC na região de integração de Carajás, o impacto do empreendimento Execução de Ações de Caráter Social, Decorrentes das Eclusas de Tucuruí gerou ações do governo federal para a mitigação de danos socioambientais causados nos municípios Bom Jesus do Tocantins, Brejo Grande do Araguaia, Marabá, Palestina do Pará, São João do Araguaia. Ao passo que, o segundo grupo de municípios formado por Canaã dos Carajás, Curianópolis, Eldorado do Carajás, Parauapebas, Piçarra, São Domingos do Araguaia, São Geraldo do Araguaia e Marabá receberam empreendimentos de infraestrutura urbano e social do PAC, com forte ausência da participação popular na deliberação, embasada em suas demandas para formulação do planejamento.

Os projetos deliberados pelas plenárias do PTP e decididos coletivamente foram marginalizados, representaram pequena participação no PPA 2008-2011, de modo que houve dissonância entre o diálogo da sociedade civil com o governo do Pará. Concomitantemente houve aproximação entre os governos municipais e o federal, por conta dos recursos financeiros do PAC. A gestão local foi subalternizada pelo poder de tomada de decisão do governo federal, em relação à decisão de implantação dos empreendimentos do PAC no Pará.

A ausência da implementação da proposta da PEC $n^{\circ}$ 233/2008, que incluiu o FNDR, comprometeu a utilização da metodologia da PNDR para o desenvolvimento regional. A aplicação dos recursos do PAC na regionalização de empreendimentos gerou expansão das heterogeneidades territoriais, os seus projetos estavam moldados em desacordo com as especificidades e regionalização territorial proposta pelo PTP no Plano Pluarianual 2008-2011, e fortaleceu a produção agropecuária e extração de minério de ferro pela espacialização produtiva na R.ı. de Carajás.

\section{REFERÊNCIAS}

ABDAL, A. Trajetórias regionais de desenvolvimento no Brasil contemporâneo: uma agenda de pesquisa. Revista brasileira de estudos urbanos e regionais. v.22, E202005, 2020. DOI 10.22296/2317-1529.rbeur.202005

ALVES, A. M., NETO, J. M. R. A nova Política Nacional de Desenvolvimento Regional - PNDR II: entre a perspectiva de inovação e a persistência de desafios. Revista Política e Planejamento Regional, Rio de Janeiro, v. 1, n. 2, julho/dezembro, 2014. ARAÚJO, T. B. Por uma política de desenvolvimento regional. In: ARAÚJO, Tânia Bacelar de. Ensaios sobre o desenvolvimento brasileiro: heranças e urgências. Rio de Janeiro: Revan: Fase, 2000.

BECKER, B. Novas territorialidades na Amazônia: desafio às políticas públicas. Bol.

Mus. Pará. Emílio Goeldi. Cienc. Hum., Belém, v. 5, n. 1, p. 17-23, jan.- abr. 2010. BRANDÃO, C. Desenvolvimento, Territórios e Escalas Espaciais: levar na devida conta as contribuições da economia política e da geografia crítica para construir a abordagem interdisciplinar. In: RIBEIRO, Maria Teresa Franco e MILANI, Carlos R. S. 
(orgs.). Compreendendo a complexidade sócioespacial contemporânea: o território como categoria de diálogo interdisciplinar. Salvador, Editora da UFBA, 2008.

BRANDÃO, C. A. Mudanças produtivas e econômicas e reconfiguração territorial no Brasil no início do Século XXI. Revista brasileira de estudos urbanos e regionais. v.21, N.2, maio-agosto, 2019.

BRASIL. CONGRESSO NACIONAL. CÂMARA DOS DEPUTADOS. Política nacional de desenvolvimento regional. Brasília: Câmara dos Deputados, Edições Câmara. 162 p. - (Série ação parlamentar; n. 374), 2008. Disponível em: http://bd.camara.gov.br/bd/handle/bdcamara/1861 Acesso: 20/11/2019.

BRASIL. Comitê Gestor do PAC. Programa de Aceleração do Crescimento: Balanço 4 anos, 2007-2010 Pará. Brasília: Comitê Gestor do PAC, s.n., 2010. Disponível em: http://pac.gov.br/pub/up/relatorio/92977484f42df916be3feadde1a42fa2.pdf Acesso: 15/12/2019.

BRASIL. Programa de Aceleração do Crescimento: 11 balanço 20112014 Pará.

Brasília: Comitê Gestor do Programa de Aceleração do Crescimento, Presidência da República, s.n., 2015. Disponível em:

http://pac.gov.br/pub/up/relatorio/d36bge5a6ff2c831cd4fb63bafe9117a.pdf Acesso: 15/12/2019.

BRASIL. Programa de Aceleração do Crescimento: 7 balanço 20152018 Pará.

Brasília: Comitê Gestor do Programa de Aceleração do Crescimento, Presidência da República, s.n., 2018 Disponível em:

http://pac.gov.br/pub/up/relatorio/ab040341229e03873053c5f7218egf78.pdf Acesso: 15/12/2019.

CANO, W. Desequilíbrios Regionais e Concentração Industrial no Brasil: 1930-1970. Campinas, SP: UNESP, 2007.

COSTA, E. J. M. Planejamento Territorial, Gestão de Políticas Públicas e Descentralização Regional: A Experiência do Estado do Pará. Revista DRd Desenvolvimento Regional em debate v. 1, n. 1, p. 120-148, jul./dez, 2011. DINIZ, C. C. Desenvolvimento Poligonal no Brasil: nem desconcentração, nem contínua polarização. Nova Economia. Belo Horizonte, v.3, no1, p. 35-64, set. 1993. GOMIDE, A e PEREIRA, A.K. Os desafios da governança da política de infraestrutura no brasil: aspectos políticos e administrativos da execução do investimento em projetos de grande vulto. In: GOMIDE, A. \& PEREIRA, A.K. (org.). Governança da política de infraestrutura - condicionantes institucionais ao investimento. Brasília: IPEA. 2018.

GUIMARÃES NETO, L. Dinâmica Regional no Brasil. Brasília, IPEA, 1997. LEITÃO, K. O. A dimensão territorial do Programa de Aceleração do Crescimento: um estudo a partir do PAC no Estado do Pará e o lugar que ele reserva à Amazônia no desenvolvimento do país. Tese (Doutorado - Área de Concentração:

Planejamento Urbano e Regional) - FAUUSP São Paulo, 2009.

LIMA, J. J. Planejamento Orçamentário Participativo e Regionalização: considerações sobre o Plano Plurianual do Estado do Pará, Brasil - 2007 a 2010.

Revista Paranaense de Desenvolvimento, Curitiba, n.119, p.169-190, jul./dez, 2010. LOTTA, G.; FAVARETO, A. Os arranjos institucionais de coordenação dos investimentos em infraestrutura no brasil: uma análise sobre seis grandes projetos do programa de aceleração do crescimento. In: GOMIDE, A. \& PEREIRA, A.K. (org.). 
Governança da política de infraestrutura - condicionantes institucionais ao investimento. Brasília: IPEA. 2018.

MDIC, Ministério da Indústria, Comércio Exterior e Serviços. Consultado em http://www.mdic.gov.br/comercio-exterior/estatisticas-de-comercio-

exterior/comex-vis/frame-municipio?municipio=1502152

PACHECO, C. A. Fragmentação da nação. Campinas, SP: UNICAMP-IE, 1998.

Secretaria de Estado de Planejamento, Orçamento e Finanças. (SEPOF). Orientação

Estratégica do Governo. Anexo, s.n., 2010. Disponível em:

http://seplad.pa.gov.br/wp-content/uploads/2015/07/anexo _ _-_lei-ppa-

orientacoes estrategicas.pdf Acesso: 10/01/2020.

Secretaria de Estado de Planejamento, Orçamento e Finanças. (SEPOF). Relatório de Avaliação do Plano Plurianual 2008-2011: Programa Finalístico. Diretoria de Planejamento Estratégico. - Belém: SEPOF, s.n., 2011a. Disponível em: http://seplad.pa.gov.br/wp-content/uploads/2015/07/ppa2008_2010_finalistico.pdf Acesso: 20/01/2020.

Secretaria de Estado de Planejamento, Orçamento e Finanças. (SEPOF). Relatório de Avaliação do Plano Plurianual 2008-2011: Programa de Política Pública. Diretoria de Planejamento Estratégico. — Belém: SEPOF, s.n., 2011b. Disponível em: http://seplad.pa.gov.br/wpcontent/uploads/2015/07/ppa2008 2010 politicapublica.pdf Acesso: 30/01/2020. Secretaria de Estado de Planejamento, Orçamento e Finanças. (SEPOF). Diretoria de Planejamento Estratégico. Relatório de Avaliação do Plano Plurianual 2008-2011/ Pará. Secretaria de Estado de Planejamento, Orçamento e Finanças. Diretoria de Planejamento Estratégico. Belém: SEPOF. Diretoria de Planejamento Estratégico, s.n., 2012. Disponível em: http://seplad.pa.gov.br/wpcontent/uploads/2015/07/relatorio_de avaliacao_dos_programas 2011.pdf Acesso: 02/02/2020.

Rafael Gonçalves Gumiero. Universidade Federal do Sul e Sudeste do Pará - UNIFESSPA/ Professor do magistério superior. gumiero84@gmail.com

Como citar: GUMIERO, Rafael Gonçalves. O planejamento territorial participativo (PTP) e o PAC em disputa para o desenvolvimento da região de integração do Carajás - Pará. Redes (St. Cruz Sul, Online), Santa Cruz do Sul, v. 25, p. 2693-2712, 2020. ISSN 1982-6745. doi:https://doi.org/10.17058/redes.v25i0.15199.

Fontes de financiamento: Pró-Reitoria de Pós-Graduação, Pesquisa e Inovação Tecnológica (Propit); Universidade Federal do Sul e Sudeste do Pará (UNIFESSPA). 